\title{
Snail homolog 1 is involved in epithelial-mesenchymal transition-like processes in human glioblastoma cells
}

\author{
CASPAR D. KÜHNÖL ${ }^{1}$, CARINA WÜRFEL ${ }^{1}$, MARTIN S. STAEGE ${ }^{1}$ and CHRISTOF KRAMM ${ }^{1,2}$ \\ ${ }^{1}$ Department of Pediatrics, University Clinic and Polyclinic for Child and Adolescent Medicine I, Martin Luther University \\ Halle-Wittenberg, D-06120 Halle; ${ }^{2}$ Division of Pediatric Hematology and Oncology, Department of Child \\ and Adolescent Health, Georg August University Göttingen, D-37075 Göttingen, Germany
}

Received June 24, 2016; Accepted January 17, 2017

DOI: $10.3892 / \mathrm{ol} .2017 .5875$

\begin{abstract}
Despite advancements in neurosurgery, chemotherapy and radiation therapy, the outcome of patients with glioblastoma remains poor. The migration of tumor cells from the primary tumor site with subsequent invasion of these cells into the surrounding normal brain tissue is frequently responsible for relapse and treatment failure. The present study hypothesized that snail homolog 1 (SNAI1), a factor critically involved in the epithelial-mesenchymal transition (EMT) of human carcinoma cells, may also contribute to an invasive EMT-like phenotype of glioblastoma cells. The majority of glioblastoma cell lines investigated in the present study expressed SNAI1 at basal levels. The present study overexpressed SNAI1 in glioblastoma cell lines by lentiviral transfer of human SNAI1 complementary DNA. In addition, the inhibition of SNAI1 expression was achieved by lentiviral transfer of a short hairpin RNA specific for SNAI1. SNAI1 overexpression increased proliferation of one of the cell lines, U251MG, but exhibited only a weak effect on the migration and invasion of glioblastoma cells. However, downregulation of SNAI1 significantly decreased the invasive capacity of all investigated cell lines. In parallel, regained expression of E-cadherin, a marker that is usually lost during EMT, was observed subsequent to SNAI1 knockdown in the glioblastoma cell lines U87MG and U251MG. The data of the present study suggest that certain key genes of the EMT in carcinoma are also involved in the migration and invasion of human glioblastoma cells.
\end{abstract}

Correspondence to: Dr Caspar D. Kühnöl, Department of Pediatrics, University Clinic and Polyclinic for Child and Adolescent Medicine I, Martin Luther University Halle-Wittenberg, 40 Ernst-Grube-Straße, D-06120 Halle, Germany

E-mail: caspar.kuehnoel@uk-halle.de

Key words: glioblastoma, epithelial-mesenchymal transition, tumor cell invasion, snail homolog 1, E-cadherin

\section{Introduction}

Approximately $1-2 \%$ of neoplastic diseases are located in the central nervous system (1). The majority of these tumors, $\sim 50-60 \%$, are gliomas that develop more often in Caucasian patients compared with those of Asian or African origin (2). The incidence of gliomas is 5-11/100,000 in Western Europe, Australia and Northern America (3). The majority of patients are older than 50 years, and males are more often affected than females (4). In Germany, every year $\sim 65$ children are diagnosed with high-grade glioma (HGG) (5). Despite advancements in neurosurgery, chemotherapy and radiation therapy, the outcome remains poor, with a median survival subsequent to diagnosis of only 14 months (6). Glioblastoma multiforme is the most common type of HGG, accounting for $\sim 50 \%$ of cases (7). The tumors may be located in all parts of the brain, but are mostly located supratentorially within the cerebral lobes (8).

The histogenetic origin of glioma cells is not clear yet. Since the beginning of the 20th century, it has been assumed that the tumor cells develop from precursor glial cells $(9,10)$. An association with neuroectodermal stem cells appears to be possible (1).

For glioblastoma, an association between clinical characteristics, histology and genetics may be observed $(11,12)$. The malignant progression is associated with an abnormal expression of proto-oncogenes and tumor-suppressor genes (7,13-15).

The poor outcome following treatment of glioblastoma is likely associated with the invasive capability of the tumor cells. Even subsequent to gross total tumor resection, vital tumor cells may have already migrated into the surrounding brain tissue, unnoticed during surgical intervention. The infiltrative growth of glioblastomas is mediated by the interplay of cell invasion, cell motility and the interaction between matrix proteins and growth factors $(16,17)$. However, models for glioma cell migration and invasion are missing. Thus, the adaptation of models from other types of tumor disease may be a promising method. In carcinoma, the change from a local carcinoma into an infiltrative and metastasizing tumor is described by the model of epithelial-mesenchymal transition (EMT) (18). Under certain circumstances, epithelial cells may adopt a mesenchymal phenotype (19-22). This change is marked by the replacement of E-cadherin (CDH1) by N-cadherin. Another important 
protein in this process is vimentin (VIM), which allows the shape of tumor cells to change, thus enabling these cells to move into the extracellular matrix (23). Notably, not all cells undergoing EMT exhibit all the EMT-specific features. Some tumors exhibit only certain EMT-typical changes or opposed phenotypical changes in terms of mesenchymal-epithelial transition (24-26).

Several EMT inducers have been described, including transforming growth factor- $\beta$ (TGF- $\beta$ ), snail homologs 1 and 2 (SNAI1/SNAI2), twist homolog 1 (TWIST1) and wingless-type mouse mammary tumor virus integration site family members (WNT) (19-33). The progression of tumors may also be part of EMT programs (34). The effect of TWIST1, a gene involved in EMT programs in carcinoma, on the invasion level of glioblastoma was previously described (35). A central role of the nuclear factor $\kappa$-light-chain-enhancer of activated B cells $(\mathrm{NF}-\kappa \mathrm{B})$ pathway in the induction of EMT has been revealed in different tumor models (36).

The present study focused on the effect of the EMT-inducer SNAI1 on the proliferation, migration and invasion of human glioblastoma cells. SNAIl belongs to the family of snail genes. The members of the snail superfamily encode for zinc finger transcriptions factors and serve an important role during the development of the mesoderm and transcriptional-repressor functions (37-40). Another function of SNAI1 is its role in cell death and cell survival programs $(41,42)$. SNAI1, as a key EMT-associated gene, is involved in several pathways, including the TGF- $\beta$, WNT, NOTCH and endothelin receptor A pathways $(39,42)$. In addition, the direct inhibition of expression of CDH1, the hallmark of EMT, is mediated by members of the snail superfamily (43).

\section{Materials and methods}

Cell culture. The human glioblastoma U87MG (44), T98G (45), LN-18 (46) and U251MG (47) cell lines were donated by Professor M. Hegi (Department of Clinical Neuroscience, University of Lausanne, Lausanne, Switzerland) and Dr W. Maes (Laboratory for Thrombosis Research, Interdisciplinary Research Facility Life Sciences Kulak, Kortrijk, Belgium), and the human embryonal kidney (HEK) 293T cell line were obtained from the American Type Culture Collection (Manassas, VA. Cells were grown in a humidified, 5\% $\mathrm{CO}_{2}$ atmosphere at $37^{\circ} \mathrm{C}$ in Dulbecco's modified Eagle's medium (DMEM; PAA Laboratories; GE Healthcare Life Sciences, Chalfont, UK) with $10 \%$ fetal calf serum (FCS; Biochrom $\mathrm{GmbH}$, Berlin, Germany), $100 \mathrm{U} / \mathrm{ml}$ penicillin and $100 \mu \mathrm{g} / \mathrm{ml}$ streptomycin (PAA Laboratories; GE Healthcare Life Sciences) in cell culture flasks. Twice a week, the cells were washed twice with PBS and detached with a trypsin/EDTA solution (0.05\% trypsin and $0.02 \%$ EDTA in PBS; PAA Laboratories; GE Healthcare Life Sciences). Subsequent to centrifugation at $350 \times \mathrm{g}$ for $7 \mathrm{~min}$, the cells were suspended in DMEM at a ratio of 1:10 in new cell culture flasks.

Overexpression of SNAIl in tumor cell lines. RNA was isolated using TRIzol reagent (Invitrogen; Thermo Fisher Scientific, Inc., Waltham, MA, USA). The complementary DNA (cDNA) of SNAI1 from the cell line T98G was amplified by reverse transcription-polymerase chain reaction (RT-PCR) using the following PCR primers: 5'-GTTCTTCTGCGCTAC TGCTG-3' (forward) and 5'-GCAGGTATGGAGAGGAAG AGG-3' (reverse). A total of $2 \mu \mathrm{l}$ cDNA was mixed with $2.5 \mu \mathrm{l}$ $10 \mathrm{X}$ buffer (Promega Corporation, Madison, WI, USA), $1.5 \mu \mathrm{l}$ $\mathrm{MgCl}_{2}$ (25 mM), $0.2 \mu \mathrm{l}$ Taq polymerase (Promega Corporation), $0.5 \mu \mathrm{l}$ dNTP mix (10 mM; Fermentas; Thermo Fisher Scientific, Inc., Pittsburgh, PA, USA), $0.25 \mu 1$ sequence-specific primers (Invitrogen; Thermo Fisher Scientific, Inc.), $2.5 \mu 1$ dimethylsulfoxide and $15.3 \mu \mathrm{l} \mathrm{H}_{2} \mathrm{O}$. The thermocycling conditions were as follows: $95^{\circ} \mathrm{C}$ for $5 \mathrm{~min} ; 35$ cycles of $94^{\circ} \mathrm{C}$ for $30 \mathrm{sec}, 60^{\circ} \mathrm{C}$ for $35 \mathrm{sec}$ and $72^{\circ} \mathrm{C}$ for $45 \mathrm{sec}$, followed by $72^{\circ} \mathrm{C}$ for $5 \mathrm{~min}$ and an infinite holding temperature of $4^{\circ} \mathrm{C}$. The PCR product was cloned into the vector pGEM-T Easy (Promega Corporation). From this vector, SNAI1 was cloned into the lentiviral vector puc2CL6IN, donated by Professor H. Hanenberg (Clinic of Pediatrics and Adolescent Medicine III, Essen University Hospital, Essen, Germany), containing a neomycin resistance cassette. Sequencing of the vector was performed as previously described (48). For lentiviral vector production, the envelope plasmid pczVSV-G and helper plasmid pCD/NL-BH, both donated by Professor H. Hanenberg, were co-transfected with puc2CL6IN-SNAI1 or the control vector puc2CL6IN into HEK293T cells. The resulting lentivirus-containing supernatants were used to infect U87MG, T98G, LN-18 and U251MG glioblastoma cells. Three independent transductions were performed. Selection of transduced cells was performed with $1 \mathrm{mg} / \mathrm{ml}$ G418 (PAA Laboratories; GE Healthcare Life Sciences).

Knockdown of SNAII in tumor cell lines. Potential short hairpin RNA sequences for knockdown of SNAI1 in tumor cells were identified using the BLOCK-iT ${ }^{\mathrm{TM}}$ RNAi Designer (Invitrogen; Thermo Fisher Scientific, Inc.). The two oligonucleotides 5'-CGCGTCCCCGCTGCAGGACTCTAATCCAT TCAAGAGATGGATTAGAGTCCTGCAGCTTTTTGGAA ATT-3' and 5'-AGGGGCGACGTCCTGAGATTAGGTAAG TTCTCTACCTAATCTCAGGACGTCGAAAAACCTTT AGC-3' were annealed and cloned in the enhanced green fluorescent protein (EGFP)-containing lentiviral vector pCL2. THPC, donated by Professor H. Hanenberg. The production of the lentiviral vectors, infection and selection of lentivirally transduced U87MG, T98G, LN-18 and U251MG cell lines was performed as aforementioned. A total of three independent transductions were performed.

$R T$-quantitative $(q) P C R$. Total RNA was isolated from glioblastoma cell lines using TRIzol reagent (Invitrogen; Thermo Fisher Scientific, Inc.). First strand cDNA synthesis was performed with $2 \mu \mathrm{g}$ total RNA using oligo-(dT) $)_{12-18}$ primers (Fermentas; Thermo Fisher Scientific, Inc.). RT was carried out with Moloney Murine Leukemia Virus Reverse Transcriptase (Fermentas; Thermo Fisher Scientific, Inc.), for $1 \mathrm{~h}$ at $37^{\circ} \mathrm{C}$. A total of $2 \mu \mathrm{l}$ cDNA was amplified by PCR [25 ( $\beta$-actin) or 35 (other targets) cycles of $94^{\circ} \mathrm{C}$ for $30 \mathrm{sec}$, $60^{\circ} \mathrm{C}$ for $35 \mathrm{sec}$ and $72^{\circ} \mathrm{C}$ for $45 \mathrm{sec}$ ] using Taq polymerase (Promega Corporation) in a final volume of $25 \mu \mathrm{l}$ in a Mastercycler personal (Eppendorf, Hamburg, Germany). All primers were purchased from Invitrogen; Thermo Fisher Scientific, Inc. The following primers were used: $\beta$-actin (ACTB) forward, 5'-GGCATCGTGATGGACTCCG-3' and reverse, 
5'-GCTGGA AGGTGGACAGCGA-3'; CDH1 forward, 5'-GCTGGAGATTAATCCGGACA-3' and reverse, 5'-ACC CACCTCTAAGGCCATCT-3'; EGFP forward, 5'-ACGTAA ACGCCCACAAGTTC-3' and reverse, 5'-AAGTCGTGCTGC TTCATGTG-3'; lymphoid enhancer-binding factor 1 (LEF1) forward, 5'-AGCACTTTTCTCCAGGGTCA-3' and reverse, 5'-CCCGTGATGGGATATACAGG-3'; neomycin phosphotransferase II forward, 5'-AGACAATCGGCTGCTC TG AT-3' and reverse, 5'-AGTGACAACGTCGAGCACAG-3'; NF- $\mathrm{kB} 1$ forward, 5'-CACCTAGCTGCCAAAGAAGG-3' and reverse, 5'-TCAGCCAGCTGTTTCATGTC-3'; SNAI1 forward, 5'-ACCCCACATCCTTCTCACTG-3' and reverse, 5'-CCGACAAGTGACAGCCAT-3'; and TWIST2 forward, 5'-CGAGGAGGAGCTCGAGAGG-3' and reverse, 5'-CTAGT GGGAGGCGGACAT-3'. RT-qPCR was performed using the Maxima SYBR-Green qPCR Master Mix kit (Fermentas; Thermo Fisher Scientific, Inc.) using the following conditions: Denaturation, $94^{\circ} \mathrm{C}$ for $45 \mathrm{sec}$; annealing, $62^{\circ} \mathrm{C}$ for $45 \mathrm{sec}$; and elongation $72^{\circ} \mathrm{C}$ for $60 \mathrm{sec}$. Each reaction was subjected to melting temperature analysis to confirm the presence of the expected products. Specific gene amplification was normalized to ACTB. Target genes and ACTB were amplified with 40 cycles using a Rotor Gene RG-3000 (Corbett Life Science; Qiagen GmbH, Hilden, Germany) and Rotor Gene 6 software version 6.1 (build 93; Corbett Life Science; Qiagen GmbH). Relative expression values were calculated using the $2^{-\Delta \Delta \mathrm{Cq}}$ method (49).

Cell proliferation assay. Analysis of cell proliferation was performed with the MTT Cell Proliferation kit (Roche Applied Science, Mannheim, Germany) according to the protocol of the manufacturer. The cells were seeded at a density of $1 \times 10^{3}$ cells/well in 96-well plates for $72 \mathrm{~h}$ in a humidified, $5 \% \mathrm{CO}_{2}$ atmosphere at $37^{\circ} \mathrm{C}$. Turnover of MTT was detected using an ELx808 microplate reader (BioTek Instruments, Inc., Winooski, VT, USA).

Cell migration assay. To analyze tumor cell migration, ThinCert cell culture inserts with a pore size of $8.0 \mu \mathrm{m}$ (Greiner Bio-One GmbH, Frickenhausen, Germany) were used. The tumor cells were washed twice with PBS, suspended in serum-free medium containing $0.2 \%$ bovine serum albumin (BSA; SERVA Electrophoresis GmbH, Heidelberg, Germany) and cultured in cell culture flasks overnight in a humidified, $5 \% \mathrm{CO}_{2}$ atmosphere at $37^{\circ} \mathrm{C}$. On the next day, the wells of a 24-well plate were filled with $600 \mu \mathrm{l}$ medium (DMEM with $10 \%$ FCS, $100 \mathrm{U} / \mathrm{ml}$ penicillin and $100 \mu \mathrm{g} / \mathrm{ml}$ streptomycin), and a ThinCert insert was placed in every well. Subsequently, $2 \times 10^{5}$ tumor cells in $200 \mu 1$ serum-free medium (DMEM with $0.2 \% \mathrm{BSA}$ ) were placed in the inserts. After $24 \mathrm{~h}$, the ThinCert inserts containing the cells were removed and placed in new wells of a 24-well plate containing $500 \mu \mathrm{l}$ trypsin/EDTA solution. The corresponding cell numbers were subsequently determined using a Neubauer chamber following staining with trypan blue (Invitrogen; Thermo Fisher Scientific, Inc.).

Matrigel invasion assay. To investigate the invasion capacity of the different glioblastoma cell lines, a Matrigel invasion chamber (BD Biosciences, Franklin Lakes, NJ, USA) was used. The cell lines were harvested and resuspended in DMEM

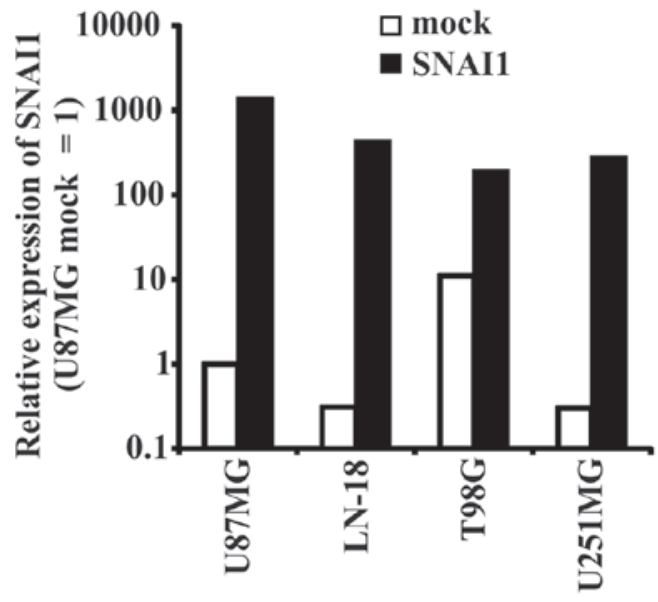

Figure 1. Expression of SNAI1 in glioblastoma cell lines. Results are presented from a single reverse transcription-quantitative polymerase chain reaction analysis, subsequent to overexpression of SNAI1 by a lentiviral vector. Control vector-transfected cells served as controls. For semi-quantitative analysis, $\beta$-actin was used as a housekeeping control, and expression in mock-transfected U87MG cells was set as 1. SNAI1, snail homolog 1 .

containing $0.1 \%$ BSA at a concentration of $5 \times 10^{4}$ cells $/ \mathrm{ml}$. Matrigel invasion and BD BioCoat Control inserts (BD Biosciences) were filled with $0.5 \mathrm{ml}$ DMEM pre-warmed to $37^{\circ} \mathrm{C}$ containing $0.1 \%$ BSA. After $2 \mathrm{~h}$ the medium was removed and the inserts were transferred into 24-well plates containing DMEM with $10 \%$ FCS as a chemoattractant. Immediately thereafter, $0.5 \mathrm{ml}$ cell suspension was added to the inside of the insert. The Matrigel invasion and control chambers were incubated for $24 \mathrm{~h}$ in a humidified, $5 \% \mathrm{CO}_{2}$ atmosphere at $37^{\circ} \mathrm{C}$. Inserts with invaded cells were stained with Diff-Quick (Medion Grifols Diagnostics AG, Düdingen, Switzerland). To determine the number of invaded cells, membranes were cut and placed on a microscope slide with a drop of immersion oil, and the cells were counted using an Axiolab light microscope (Zeiss GmbH, Jena, Germany). To calculate the percentage of invading cells, the mean number of cells invading into the Matrigel insert membrane was divided by the mean number of cells migrating through the control inserts and multiplied by 100 .

Statistical analysis. Statistical analysis was performed using Microsoft Excel 2010 (version 14.0.7128.5000; Microsoft Corporation, Redmont, WA, USA), Student's $t$-test was used to analyze differences. $\mathrm{P}<0.05$ was considered to indicate a statistically significant difference.

\section{Results}

Modulation of EMT-associated genes by overexpression of SNAII in glioblastoma cells. To investigate the effect of SNAI1 on glioblastoma cells, glioblastoma U87MG, T98G, LN-18 and $\mathrm{U} 251 \mathrm{MG}$ cell lines were transduced with lentiviral vectors allowing the overexpression or inhibition of SNAI1. Neither SNAI1 overexpression nor inhibition changed the microscopic appearance (size and shape) of the cells. SNAI1 overexpression was confirmed by RT-qPCR analysis (Fig. 1). In all used glioma cell lines, the expression of SNAI increased following transduction. A significantly $(\mathrm{P}<0.05)$ increased proliferation 

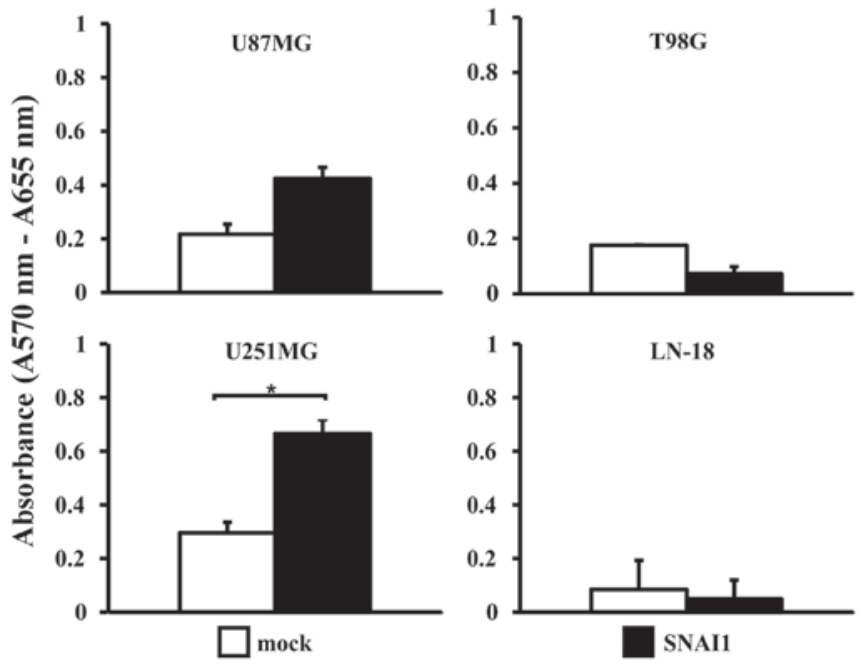

Figure 2. Effect of SNAI1 on the proliferation of glioblastoma cells Proliferation of the indicated cell lines was assessed by MTT assay. Control vector-transfected cells and cells with SNAI1 overexpression were analyzed. Means and standard deviations from triplicate experiments are presented. ${ }^{*} \mathrm{P}<0.05$. SNAI1, snail homolog 1.
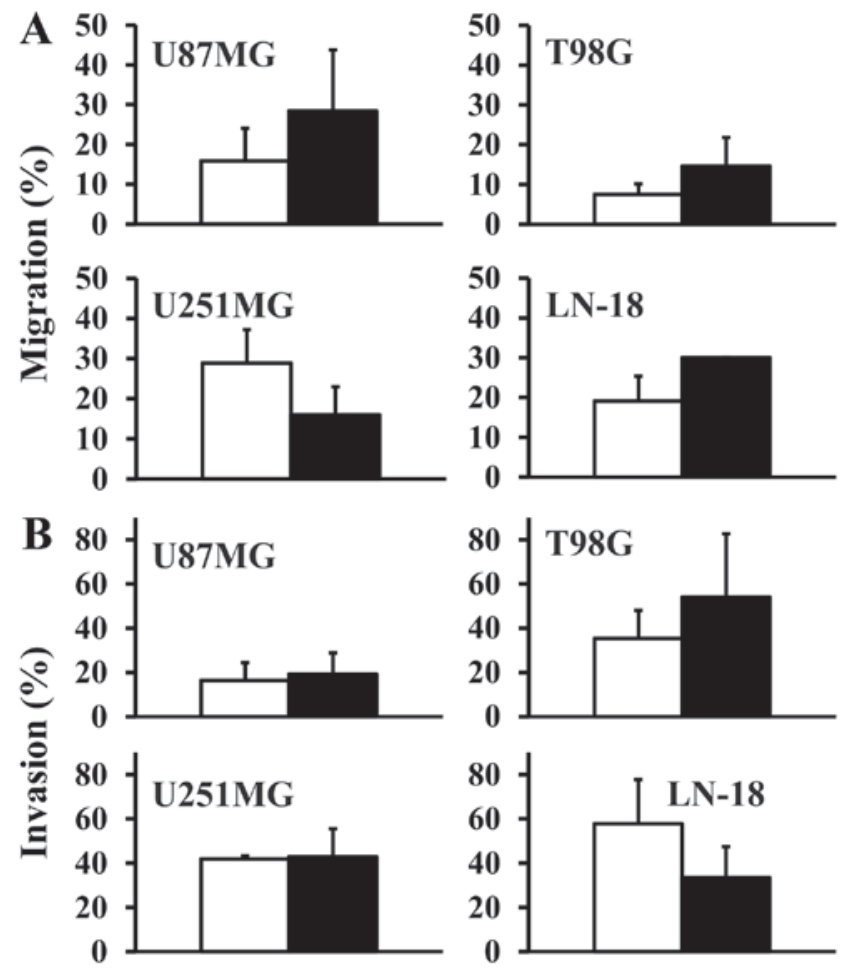

\section{$\square$ mock $\square$ SNAI1}

Figure 3. Effect of SNAI1 on the migration and invasion of glioblastoma cells. (A) The migration of the indicated cell lines was assessed. Control vector-transfected cells and cells with SNAI1 overexpression were analyzed. Means and standard deviations from three independent experiments are presented. (B) The invasion ability of the indicated cell lines was assessed by Matrigel assay. Control vector-transfected cells and cells with SNAI1 overexpression were analyzed. Means and standard deviations of three independent experiments are presented. SNAI1, snail homolog 1.

rate of SNAI1-overexpressing U251MG cells compared with the vehicle control (Fig. 2) was observed. The three other cell lines exhibited no significant proliferative changes upon SNAI1 overexpression. Furthermore, none of the cell lines

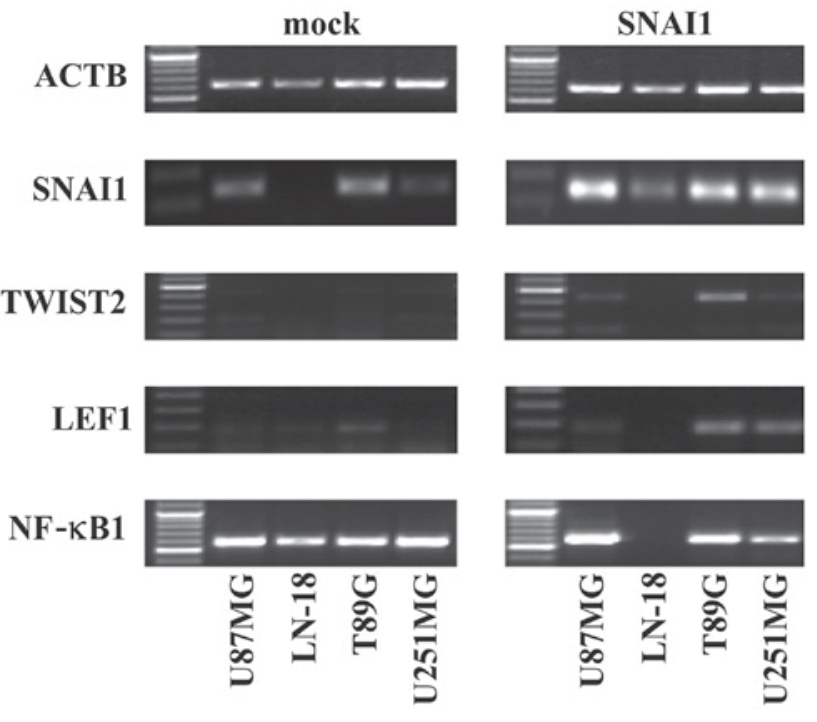

Figure 4. Expression of epithelial-mesenchymal transition target genes in SNAI1-transgenic cells. Representative results from reverse transcription-polymerase chain reaction experiments with specific primers for the indicated genes are presented. ACTB was used as a housekeeping control. Control vector-transfected cells and cells overexpressing SNAI1 were compared. One out of two experiments with identical results is presented. ACTB, $\beta$-actin; SNAI1, snail homolog 1; TWIST, twist homolog; LEF1, lymphoid enhancer-binding factor 1; NF- $\mathrm{kB}$, nuclear factor $\kappa$-light-chain-enhancer of activated B cells.

exhibited significant changes on their migration rate, although there was a tendency towards a relative higher migration rate in the U87MG, T98G and LN-18 cell lines (Fig. 3A). Similarly, no significant differences in the invasion rate were detectable when comparing each cell type to the control (Fig. 3B).

The present study investigated whether EMT target genes may be affected by the overexpression of SNAI1 in glioblastoma cells. The regulation of TWIST2 in three of four glioma cell lines, U87MG, T98G and U251MG, upon SNAI1 overexpression (Fig. 4) was observed. In addition, RT-PCR revealed an increased expression of NF- $\mathrm{kB} 1$ in SNAI1-overexpressing U87MG and T98G cells. On the contrary, the overexpression of SNAI1 resulted in the decreased expression of NF- $\kappa B 1$ in LN-18 cells and U251MG cells. LEF1 exhibited low expression in untreated U87MG, LN-18 and T98G cells. An increased LEF1 expression was also detected in T98G and U251MG cells upon SNAI1 overexpression (Fig. 4). No differences were observed for VIM, which was stably detectable in U251MG, T98G and U87MG cells. CDH1 was absent from all cell lines independent from SNAI1 transduction (data not shown; see also below; Fig. 5A).

Re-induction of CDH1 subsequent to knockdown of SNAII in glioblastoma cells. Upon SNAI1 inhibition, as confirmed by RT-PCR analysis (Fig. 5A), a significantly higher proliferation rate in the cell line T98G was observed. In all the other cell lines, no significant effect on cellular proliferation was observed (Fig. 5B). Loss of CDH1 is a central step during EMT, accompanying the establishment of a highly infiltrative and metastasizing tumor phenotype (50). Thus, it was notable to observe that two out of four cell lines (U87MG and U251MG; Fig. 5A) regained CDH1 expression upon inhibition of SNAI1. No changes in the expression of VIM were observed (data 
A

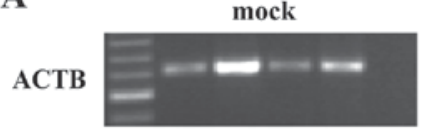

SNAI1

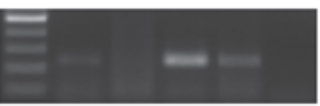

CDH1
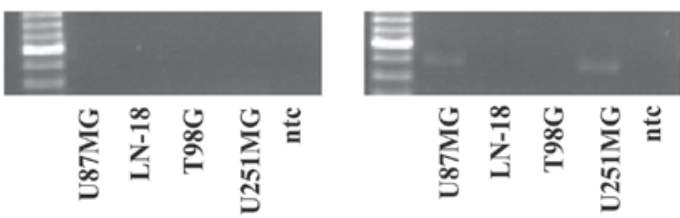

B
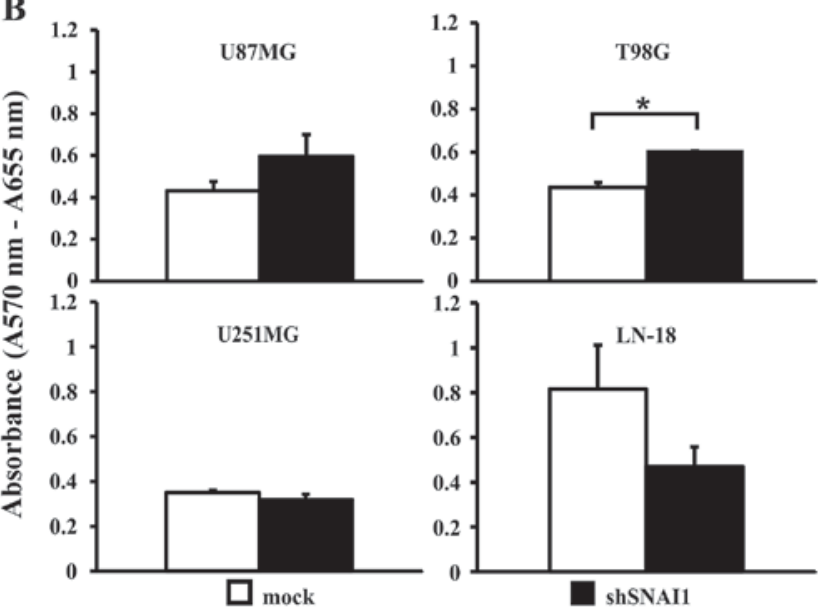

Figure 5. Knockdown of SNAI1 in glioblastoma cells and re-expression of CDH1. (A) The expression of SNAI1 in the indicated cell lines was assessed by reverse transcription-PCR. Representative results from control vector-transfected cells and cell lines with knockdown of SNAI1 (shSNAI1) are presented. PCR with primers with specificity for enhanced green fluorescent protein were used to prove that transduction of the different cell lines had occurred. ACTB was used as a housekeeping control. (B) The proliferation of the indicated cell lines was assessed by MTT assay. Control vector-transfected and SNAI1 knockdown cells were analyzed. Means and standard deviations from triplicate experiments are presented. ${ }^{*} \mathrm{P}<0.05$. SNAI1, snail homolog 1; PCR, polymerase chain reaction; ACTB, $\beta$-actin; CDH1, E-cadherin; ntc, no template control; sh, short hairpin.

not shown). The migration rate appeared relatively decreased compared with the mock transfected cells in the cell lines T98G, LN-18 and U251MG, but the differences did not reach significance (Fig. 6A). In U87MG cells, the migration rate was enhanced. However, the invasion capability significantly decreased in all four human glioma cell lines subsequent to SNAI1 inhibition (Fig. 6B).

\section{Discussion}

EMT represents a well-established model explaining the switch from a local into an infiltrating and metastasizing carcinoma phenotype on a signal transduction level (50). The present study investigated if this model may also be adaptable to human glioblastoma cells, which are characterized by extensively infiltrating tumor cells $(16,17)$.

A key gene of EMT is SNAI, which is involved in different signaling pathways that downregulate $\mathrm{CDH} 1$ expression as a hallmark of EMT (50). A baseline SNAI1 expression in all investigated four human glioma cell lines, U87MG, T98G,
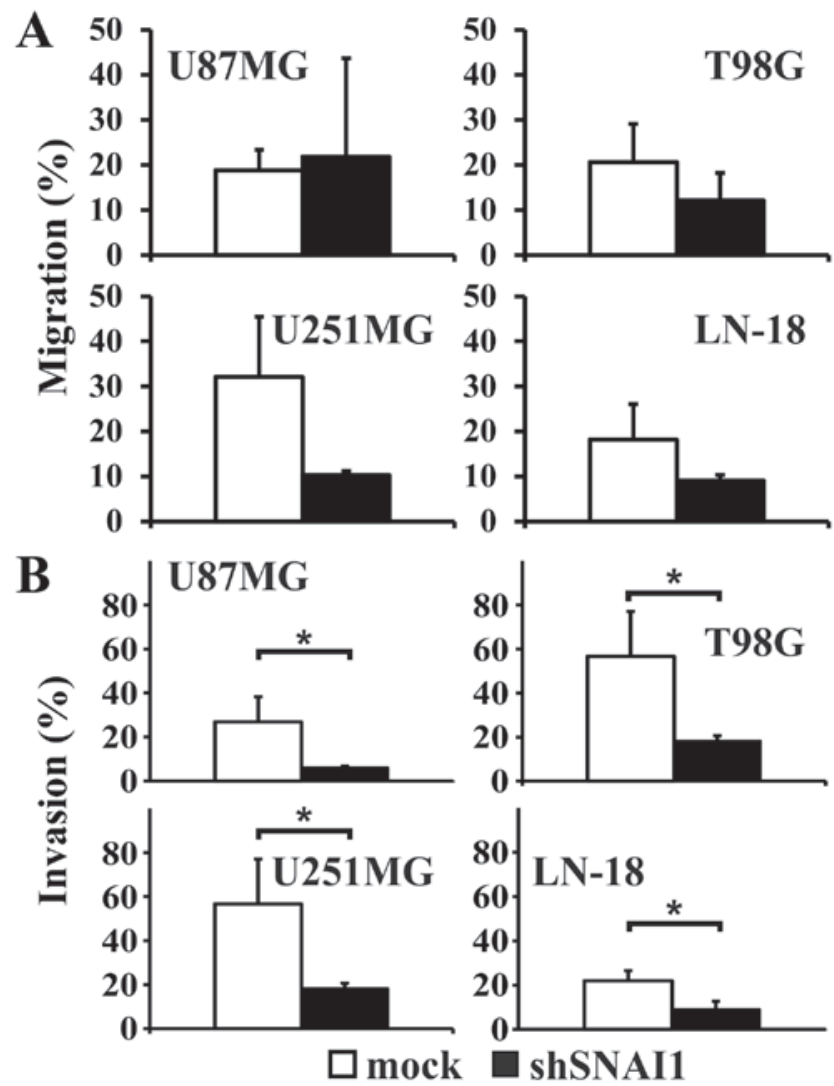

Figure 6. Effect of knockdown of SNAI1 on the migration and invasion of glioblastoma cells. (A) The migration of the indicated cell lines was assessed. Control vector-transfected and SNAI1 knockdown cells were analyzed. Means and standard deviations from triplicates are presented. (B) The invasion capacity of the indicated cell lines was assessed by Matrigel assay. Results from control vector-transfected cells and the cell lines subsequent to knockdown of SNAI1 of three independent experiments are presented as the mean + standard deviation. ${ }^{*} \mathrm{P}<0.05$. SNAI1, snail homolog 1 ; sh, short hairpin.

U251MG and LN-18, was observed in the present study. High SNAI1 baseline expression may contribute to the infiltrative and migratory phenotype of glioblastoma cells, similar to EMT-associated functions of SNAI in carcinoma cells (51). Growth inhibition of U87MG cells subsequent to knockdown of SNAI1 has been described (37). The present study did not observe inhibition of proliferation subsequent to SNAI1 knockdown in any of the investigated cell lines. This divergence may be a consequence of experimental differences. For instance, viral transduction was used for genetic engineering, whereas in the study by Han et al (37), transfection of small interfering RNA was performed. In addition, proliferation was not investigated directly in the present study. Han et al (37) used a viability assay that depends on an intact respiratory chain, whereas the present study used an assay that depends on intact glycolysis. The effect of SNAI1 on the proliferation of glioma cells requires additional investigation.

The SNAI baseline expression may also be responsible for the observation of the present study that the additional increase in SNAI expression subsequent to lentiviral gene transfer did not result in significantly increased cell migration or invasion in any investigated cell line, although there was at least a tendency towards increased cell migration subsequent to SNAI overexpression in the majority of the cell lines. 
RT-PCR analyses of EMT target genes in the four glioblastoma cell lines also exhibited heterogeneous results. Mock transfected cell lines displayed no baseline expression of TWIST2, but the overexpression of SNAI1 induced a high expression of TWIST2 in three of four cell lines. TWIST2 is known as a direct inducer of EMT $(52,53)$. In addition, there is evidence that TWIST1 may act as a potential oncogene in gliomas exhibiting an increased expression of TWIST1 during the transformation from low-grade glioma to HGG (54). There appear to be different signaling pathways involved in TWIST activation upon the induction of SNAI expression in the various glioblastoma cell models used in the present study. In U87MG and T98G cells, the activation of TGF- $\beta$-dependent signaling pathways appeared to be involved, as these cells exhibited increased NF- $\kappa \mathrm{B} 1$ expression upon induction of SNAI expression; $\mathrm{NF}-\kappa \mathrm{B} 1$ is one of the key genes of the TGF- $\beta$ pathway, but may also be involved in other pathways (55). However, in LN-18 and U251MG cells, NF- $\mathrm{BB} 1$-associated signaling did not appear to be driving TWIST expression subsequent to SNAI gene transfer. In these cell lines, NF- $\mathrm{BB} 1$ expression decreased subsequent to the overexpression of SNAI1.

In T98G and U251MG cells, the WNT signaling pathway appears to be activated subsequent to SNAI gene transfer. In the present study, increased expression of TWIST and LEF1 as target genes of the canonical WNT pathway was observed. However, the present study did not additionally corroborate if the activation of WNT signaling led to TWIST expression or vice versa. The involvement of WNT and TWIST in EMT is well known, and it has been shown that TWIST may activate canonical WNT signaling in carcinoma (56).

However, the involvement of SNAI1 in EMT-like pathways appeared much clearer following inhibition of SNAI expression compared with overexpression of SNAI1. Subsequent to the inhibition of SNAI1 by lentiviral knockdown, re-expression of CDH1 in U87MG and U251MG cells was observed. Since in carcinoma cells the downregulation of CDH1 expression represents the hallmark of EMT induction, the finding of the re-induction of CDH1 expression subsequent to SNAI inhibition may provide indirect evidence that there may be an EMT-like phenotype in human glioblastoma. CDH1 was not expressed in wild-type or SNAI1-overexpressing glioblastoma cells, but was induced in half of the cell lines subsequent to the knockdown of SNAI1. This observation is in agreement with the significantly lower cellular invasion capabilities observed subsequent to the inhibition of SNAI expression.

Cell lines are suitable models for glioblastoma research in vitro $(57,58)$. However, cell culture-dependent effects may also be observed with respect to the behavior of tumor cells, and certain widely used tumor cell lines do not exhibit the typical glioblastoma growth pattern in xenotransplantation models (59). Therefore, the analysis of SNAI1 and interacting factors in patient-derived material is required.

Taken together, the data of the present study may indicate that EMT-like processes similar to those in carcinoma may also occur in human glioblastoma, thereby potentially contributing to their aggressive and invasive phenotype. However, systematic investigation of the key EMT genes and associated signaling pathways is required to obtain a more comprehensive overview, as the signaling network may be the same as that in carcinoma or there may be differences. In addition, an analysis of the involved factors at the protein level will increase the level of information about the relevant pathways.

\section{Acknowledgements}

The authors would like to thank Professor Monika Hegi (Department of Clinical Neuroscience, University of Lausanne, Lausanne, Switzerland) and Dr Wim Maes (Laboratory for Thrombosis Research, Interdisciplinary Research Facility Life Sciences Kulak, Kortrijk, Belgium) for providing the glioblastoma cell lines, as well as Professor Helmut Hanenberg (Clinic of Pediatrics and Adolescent Medicine III, Essen University Hospital, Essen, Germany) for providing the vectors pczVSV-G, pCD/NL-BH, pCL2.THPC, pcl2.THPC and puc2CL6IN.

\section{References}

1. Kleihues P, Louis DN, Scheithauer BW, Rorke LB, Reifenberger G, Burger PC and Cavenee WK: The WHO classification of tumours of the nervous system. J Neuropathol Exp Neurol 61: 215-225, 2002.

2. Ohgaki $\mathrm{H}$ and Kleihues P: Epidemiology and etiology of gliomas. Acta Neuropathol 109: 93-108, 2005.

3. Legler JM, Ries LA, Smith MA, Warren JL, Heineman EF, Kaplan RS and Linet MS: Cancer surveillance series (corrected): Brain and other central nervous system cancers: Recent trends in incidence and mortality. J Natl Cancer Inst 91: 1382-1390, 1999.

4. Schwartzbaum JA, Fisher JL, Aldape KD and Wrensch M: Epidemiology and molecular pathology of glioma. Nat Clin Pract Neurol 2: 494-503, 2006.

5. Kramm C, Rausche U, Butenhoff S, Kühnöl C, Kunze C, Kortmann R, Wolff J and van Gool S: Hochmaligne Gliome im Kindes-und Jugendalter. Monatschr Kinderheilkd 156: 1201-1207, 2008.

6. Stupp R and Weber DC: The role of radio- and chemotherapy in glioblastoma. Onkologie 28: 315-317, 2005.

7. Ohgaki $\mathrm{H}$ and Kleihues P: Population-based studies on incidence, survival rates and genetic alterations in astrocytic and oligodendroglial gliomas. J Neuropathol Exp Neurol 64: 479-489, 2005

8. Larjavaara S, Mäntylä R, Salminen T, Haapasalo H, Raitanen J, Jääskeläinen J and Auvinen A: Incidence of gliomas by anatomic location. Neuro Oncol 9: 319-325, 2007.

9. Smith MT, Ludwig CL, Godfrey AD and Armbrustmacher VW: Grading of oligodendrogliomas. Cancer 52: 2107-2114, 1983.

10. Bailey P and Cushing H: Microchemical color reactions as an Aid to the Identification and classification of brain tumours. Proc Natl Acad Sci USA 11: 82-84, 1925.

11. Collins VP: Gene amplification in human gliomas. Glia 15: 289-296, 1995.

12. Dirks PB and Rutka JT: Current concepts in neuro-oncology: The cell cycle - a review. Neurosurgery 40: 1000-1015, 1997.

13. Ohgaki H, Dessen P, Jourde B, Horstmann S, Nishikawa T, Di Patre PL, Burkhard C, Schüler D, Probst-Hensch NM, Maiorka PC, et al: Genetic pathways to glioblastoma: A population-based study. Cancer Res 64: 6892-6899, 2004.

14. Schmidt MC, Antweiler S, Urban N, Mueller W, Kuklik A, Meyer-Puttlitz B, Wiestler OD, Louis DN, Fimmers R and von Deimling A: Impact of genotype and morphology on the prognosis of glioblastoma. J Neuropathol Exp Neurol 61: 321-328, 2002.

15. Nozaki M, Tada M, Kobayashi H, Zhang CL, Sawamura Y, Abe H, Ishii N and Van Meir EG: Roles of the functional loss of p53 and other genes in astrocytoma tumorigenesis and progression. Neuro Oncol 1: 124-137, 1999.

16. Rao JS: Molecular mechanisms of glioma invasiveness: The role of proteases. Nat Rev Cancer 3: 489-501, 2003.

17. Maria BL, Eskin TA and Quisling RG: Brainstem and other malignant gliomas: II. Possible mechanisms of brain infiltration by tumour cells. J Child Neurol 8: 292-305, 1993.

18. Micalizzi DS, Farabaugh SM and Ford HL: Epithelialmesenchymal transition in cancer: Parallels between normal development and tumour progression. J Mammary Gland Biol Neoplasia 15: 117-134, 2010. 
19. Townsend TA, Wrana JL, Davis GE and Barnett JV: Transforming growth factor-beta-stimulated endocardial cell transformation is dependent on Par6c regulation of RhoA. J Biol Chem 283 : 13834-13841, 2008.

20. Greenburg G and Hay ED: Epithelia suspended in collagen gels can lose polarity and express characteristics of migrating mesenchymal cells. J Cell Biol 95: 333-339, 1982.

21. Yang $\mathbf{J}$ and Weinberg RA: Epithelial-mesenchymal transition: At the crossroads of development and tumour metastasis. Dev Cell 14: 818-829, 2008.

22. Savanger P: Leaving the neighbourhood: Molecular mechanisms involved during epithelial-mesenchymal transition. Bioessays 23: 912-923, 2001

23. Mendez MG, Kojima S and Goldman RD: Vimentin induces changes in cell shape, motility and adhesion during the epithelial to mesenchymal transition. FASEB J 24: 1838-1851, 2010.

24. Yilmaz M and Christofori G: EMT, the cytoskeleton, and cancer cell invasion. Cancer Metastasis Rev 28: 15-33, 2009.

25. Boyer B, Vallès AM and Edme N: Induction and regulation of epithelial-mesenchymal transition. Biochem Pharmacol 60: 1091-1099, 2000

26. Chaffer CL, Thompson EW and Williams ED: Mesenchymal to epithelial transition in development and disease. Cells Tissues Organs 185: 7-19, 2007.

27. Ozdamar B, Bose R, Barrios-Rodiles M, Wang HR, Zhang Y and Wrana JL: Regulation of the polarity protein Par6 by TGFbeta receptors controls epithelial cell plasticity. Science 307 1603-1609, 2005.

28. Ikenouchi J, Matsuda M, Furuse M and Tsukita S: Regulation of tight junctions during the epithelium-mesenchyme transition: Direct repression of the gene expression of claudins/occludin by Snail. J Cell Sci 116: 1959-1967, 2003.

29. Zavadil J and Böttinger EP: TGF-beta and epithelial-to-mesenchymal transitions. Oncogene 24: 5764-5774, 2005.

30. Huber MA, Kraut N and Beug H: Molecular requirements for epithelial-mesenchymal transition during tumour progression. Curr Opin Cell Biol 17: 548-558, 2005.

31. Savagner P, Yamada KM and Thiery JP: The zinc-finger protein slug causes desmosome dissociation, an initial and necessary step for growth factor-induced epithelial-mesenchymal transition. J Cell Biol 137: 1403-1419, 1997.

32. Yang J, Mani SA, Donaher JL, Ramaswamy S, Itzykson RA, Come C, Savagner P, Gitelman I, Richardson A and Weinberg RA: Twist, a master regulator of morphogenesis, plays an essential role in tumour metastasis. Cell 117: 927-939, 2004.

33. Kim K, Lu Z and Hay ED: Direct evidence for a role of beta-catenin/LEF-1 signaling pathway in induction of EMT. Cell Biol Int 26: 463-476, 2002.

34. Logullo AF, Nonogaki S, Pasini FS, Osório CA, Soares FA and Brentani MM: Concomitant expression of epithelial-mesenchymal transition biomarkers in breast ductal carcinoma: Association with progression. Oncol Rep 23: 313-320, 2010.

35. Mikheeva SA, Mikheev AM, Petit A, Beyer R, Oxford RG, Khorasani L, Maxwell JP, Glackin CA, Wakimoto H, GonzálezHerrero I, et al: TWIST1 promotes invasion through mesenchymal change in human glioblastoma. Mol Cancer 9: 194, 2010.

36. Zhu QC, Gao RY, Wu W and Qin HL: Epithelial-mesenchymal transition and its role in the pathogenesis of colorectal cancer. Asian Pac J Cancer Prev 14: 2689-2698, 2013.

37. Han SP, Kim JH, Han ME, Sim HE, Kim KS, Yoon S, Baek SY, Kim BS and Oh SO: SNAI1 is involved in the proliferation and migration of glioblastoma cells. Cell Mol Neurobiol 31: 489-496, 2011.

38. Nieto MA: The snail superfamily of zinc-finger transcription factors. Nat Rev Mol Cell Biol 3: 155-166, 2002.

39. Barrallo-Gimeno A and Nieto MA: The Snail genes as inducers of cell movement and survival: implications in development and cancer. Development 132: 3151-3161, 2005

40. Paznekas WA, Okajima K, Schertzer M, Wood S and Jabs EW: Genomic organization, expression and chromosome location of the human SNAIL gene (SNAI1) and a related processed pseudogene (SNAI1P). Genomics 62: 42-49, 1999.
41. Inukai T, Inoue A, Kurosawa H, Goi K, Shinjyo T, Ozawa K, Mao M, Inaba T and Look AT: SLUG, a ces-1-related zinc finger transcription factor gene with antiapoptotic activity, is a downstream target of the E2A-HLF oncoprotein. Mol Cell 4: 343-352, 1999.

42. Rosanò L, Cianfrocca R, Spinella F, Di Castro V, Nicotra MR, Lucidi A, Ferrandina G, Natali PG and Bagnato A: Acquisition of chemoresistance and EMT phenotype is linked with activation of the endothelin A receptor pathway in ovarian carcinoma cells. Clin Cancer Res 17: 2350-2360, 2011.

43. Thiery JP and Sleeman JP: Complex networks orchestrate epithelial-mesenchymal transition. Nat Rev Mol Cell Biol 7: 131-142, 2006.

44. Beckman G, Beckman L, Pontén J and Westermark B: G-6-PD and PGM phenotypes of 16 continuous human tumor cell lines. Evidence against cross-contamination and contamination by HeLa cells. Hum Hered 21: 238-241, 1971.

45. Stein GH: T98G: An anchorage-independent human tumor cell line that exhibits stationary phase G1 arrest in vitro. J Cell Physiol 99: 43-54, 1979.

46. Diserens AC, de Tribolet N, Martin-Achard A, Gaide AC, Schnegg JF and Carrel S: Characterization of an established human malignant glioma cell line: LN-18. Acta Neuropathol 53: 21-28, 1981

47. Pontén J and Macintyre EH: Long term culture of normal and neoplastic human glia. Acta Pathol Microbiol Scand 74: 465-486, 1968.

48. Neumann I, Foell JL, Bremer M, Volkmer I, Korholz D, Burdach S and Staege MS: Retinoic acid enhances sensitivity of neuroblastoma cells for imatinib mesylate. Pediatr Blood Cancer 55: 464-470, 2010.

49. Livak KJ and Schmittgen TD: Analysis of relative gene expression data using real-time quantitative PCR and the 2(-Delta Delta C(T)) Method. Methods 25: 402-408, 2001.

50. Heerboth S, Housman G, Leary M, Longacre M, Byler S, Lapinska K, Willbanks A and Sarkar S: EMT and tumor metastasis. Clin Transl Med 4: 6, 2015.

51. Casas E, Kim J, Bendesky A, Ohno-Machado L, Wolfe CJ and Yang J: Snail2 is an essential mediator of Twist1-induced epithelial mesenchymal transition and metastasis. Cancer Res 71: 245-254, 2011.

52. Li Y, Wang W, Wang W, Yang R, Wang T, Su T, Weng D, Tao T, Li W, Ma D, et al: Correlation of TWIST2 up-regulation and epithelial-mesenchymal transition during tumorigenesis and progression of cervical carcinoma. Gynecol Oncol 124: 112-118, 2012.

53. Fang X, Cai Y, Liu J, Wang Z, Wu Q, Zhang Z, Yang CJ, Yuan L and Ouyang G: Twist 2 contributes to breast cancer progression by promoting an epithelial-mesenchymal transition and cancer stem-like cell self-renewal. Oncogene 30: 4707-4720, 2011.

54. Elias MC, Tozer KR, Silber JR, Mikheeva S, Deng M, Morrison RS, Manning TC, Silbergeld DL, Glackin CA, Reh TA, et al: TWIST is expressed in human gliomas and promotes invasion. Neoplasia 7: 824-837, 2005.

55. Maier HJ, Schmidt-Strassburger U, Huber MA, Wiedemann EM, Beug $\mathrm{H}$ and Wirth T: NF-kappaB promotes epithelial-mesenchymal transition, migration and invasion of pancreatic carcinoma cells. Cancer Lett 295: 214-228, 2010.

56. Luo GQ, Li JH, Wen JF, Zhou YH, Hu YB and Zhou JH: Effect and mechanism of the Twist gene on invasion and metastasis of gastric carcinoma cells. World J Gastroenterol 14: 2487-2493, 2008.

57. Wick W, Weller M, Weiler M, Batchelor T, Yung AW and Platten M: Pathway inhibition: Emerging molecular targets for treating glioblastoma. Neuro Oncol 13: 566-579, 2011.

58. Niclou SP, Fack F and Rajcevic U: Glioma proteomics: Status and perspectives. J Proteomics 73: 1823-1838, 2010.

59. Frosina G: Development of therapeutics for high grade gliomas using orthotopic rodent models. Curr Med Chem 20: 3272-3299, 2013. 